\title{
Alternative Perspectives on Leadership: Integrating Transformational Leadership with Confucian Philosophy
}

\author{
Glenn Stone' ${ }^{1}$, Cynthia Conley ${ }^{1}$, Yibing Luo ${ }^{2}$ \\ ${ }^{1}$ Department of Social Work, Ball State University, Muncie, USA \\ ${ }^{2}$ Private Consultant, New York, USA \\ Email: gestone@bsu.edu
}

Received 25 April 2014; revised 23 May 2014; accepted 28 May 2014

Copyright @ 2014 by authors and Scientific Research Publishing Inc.

This work is licensed under the Creative Commons Attribution International License (CC BY). http://creativecommons.org/licenses/by/4.0/

(c) (i) Open Access

\begin{abstract}
This paper presents a model for integrating elements of Transformational Leadership with Confucian Philosophy. The various concepts of each perspective are discussed with special emphasis on efforts to note similarities in the two perspectives. Examples of how leaders could apply the integration of these two perspectives are presented for those working in the social service field.
\end{abstract}

\section{Keywords}

\section{Leadership, Social Services, Transformational Leadership, Confucious}

\section{Introduction}

The literature on "leadership" in social work administrative practice is relatively scant at this point in time (Kirkpatrick \& Ackroyd, 2003). Instead, there has been an emphasis on the management and supervisory aspects of social work administrative practice (Lawler, 2008). Mizrahi \& Berger (2001) maintain that management is best understood as a means of "getting the work done" (p. 171). Bennis \& Nanus (1985) have stated that managing means to accomplish activities and manage routines, usually within a set of contractual exchanges. In essence, it is the technical and operational aspects of the work. On the other hand, leadership is more about "setting the direction, standards, and vision for an organization” (Mizrahi \& Berger, 2001: p. 171). Mary (2005) states that leadership "involves influencing others and creating visions for change, or, empowerment" (p. 106). Bennis \& Nanus (1985) simply suggest that "managers are people who do things right and leaders are people who do the right thing” (p. 221).

As the field of social work administration began to acknowledge the distinction between management and 
leadership there developed an increased interest in further exploration of leadership within social work education and social work administrative practice (Lagos, 2004; Lawler, 2008). According to Mizrahi \& Berger (2005), "leadership in the social work profession has taken on greater importance in response to social, cultural, economic, and political forces that shape social services provision” (p. 155). Mizrahi \& Berger (2001) note that "vision" is a critical element of leadership. They suggest that "vision" is affected by the personal orientation of the leader, the internal-external environment, professional values, and the political and economic climate in which a leader works. As increased emphasis is placed upon leadership over management, it becomes apparent that the administrative behaviors of a leader may be shaped less by technical decision-making tools, but more by the "vision" held by the respective leader. As this is the case, it seems like an opportunity is emerging for social workers to explore a range of worldviews that could be internalized in such a manner as to affect their leadership vision for their agency and/or community. This could mean synthesizing information offered by western culture perspectives on leadership with other cultural views on leadership. In this paper, the teachings of the Chinese philosopher Confucius are presented in relationship to the four components of the western culture-based transformational leadership theory. These four components are: inspirational motivation, intellectual stimulation, idealized influence, and individual consideration (Bass, 1985). These components will be used to provide practical suggestions for social work leaders to find ways to incorporate both western theoretical concepts with the eastern philosophical tenants of Confucius in order to enhance their leadership capabilities.

\section{Confucius}

\subsection{Personal History}

Confucius is the Latinized name of Kung Zi, or Master King. He was born in $551 \mathrm{BC}$ in the state of Lu, in the southern part of the present Shandong province in eastern China. He lived in a period of Chinese history known as the Warring States. There were hundreds of feudal states in conflict with one another; however it was also a period of great freedom of thought (Fernandez, 2004). Confucius' aim was to bring about social reforms through education to bring about an ideal society through the promotion of ideal ways of life and full development of the individual personality.

He was an advocate of universal education and thought that government positions should go to the best qualified individuals (Chin, 2007). According to Confucius, every individual had the potential to be educable. This was a significant break from tradition, as before him, only the nobility had the opportunity to receive an education. Many of his followers were from unprivileged backgrounds and he strove to teach them to become virtuous citizens who would be useful to the state and society (Chin, 2007).

\subsection{Leadership Perspectives}

Within the Confucian perspective, leadership is viewed as the emergent quality of one's character that is emitted and in turn encourages others to want to follow. In essence, it is principally built upon the respect and trust a leader is able to create. A critical condition for leadership is to strive toward near-perfect behaviors. A true leader is willing and able to serve as a model to followers. While Confucius held that leadership resides within the person, he did not believe that one is born with those qualities; on the contrary, these qualities are acquired through a conscious effort of self-improvement and unvarying learning (Fernandez, 2004). Therefore, true leadership is not reserved for a few, but is open to all who are willing to work hard on their journey to becoming virtuous.

It may be obvious at this point that becoming a leader within the Confucian perspective is a significant challenge. It is no easy task to engage in constant self-improvement and no one starts this type of journey anywhere but the beginning, that is, the "low ground" (Chan, 2008). Fernandez (2004) notes that the Confucian path to leadership has two aims - an internal goal of individual perfection; and an external goal of achieving social harmony through the exemplary conduct of the leader.

\subsection{Transformational Leadership}

An important theory of leadership is based upon the writings of Bass (1985) and is termed "transformational leadership.” According to Bass, transformational leadership occurs when a leader transforms, or changes, his or her followers in ways that result in followers trusting the leader, performing behaviors that contribute to the achievement of organizational goals, and being motivated to perform at a high level. Transformational leaders 
increase subordinates' awareness of the importance of their tasks and the importance of performing well, make subordinates aware of their needs for personal growth, development, and accomplishment, and motivate their subordinates to work for the good of the organization rather than exclusively for their own personal gain or benefit. In essence, a primary premise is that transformational leaders can achieve agency goals through meeting the needs of the follower. These particular needs are not based on quid pro quo transactions (as in transactional leadership), but higher order needs. These needs are those of the total person and are closely aligned with the internal motivational factors of the follower.

\subsection{Transformational Leadership and Confucian Philosophy}

There are four key components to transformational leadership theory: (a) idealized influence, (b) intellectual stimulation, (c) inspirational motivation, and (d) individualized consideration (Bass, 1985). Each of these will now be discussed with comments regarding the relationship with Confucian philosophy noted.

\subsubsection{Idealized Influence}

The concept of idealized influence is similar to what might generally be thought of as charisma. It is important to note that charisma is not always to be viewed in a negative light. Some even suggest that charisma is a vital element to successful transformational leadership (Aaltio-Marjosola \& Takala, 2000). From this perspective, the application of idealized influence refers to a "leader's ability to generate enthusiasm and draw people together around a vision through self-confidence and emotional appeal” (Fisher, 2009: p. 362).

At a more concrete level, a leader can become a more idealized influence by modeling desirable role behaviors within the organization and culture. By demonstrating that he/she is a positive role model, a leader can bring about trust, respect, and even admiration of followers. Within this paradigm, the true transformational leader will demonstrate dedication, a strong sense of purpose and perseverance, and will work to enable followers to achieve a sense of empowerment and ownership (Van Eeden, Cilliers, \& Van Deventer, 2008). For the transformational leader, empowerment is more than simply expanding the range of involvement by followers; it is motivational and enabling, emphasizing a new awareness and transformation of the person. Here we can draw a parallel to the works of Confucius and his writing about his concept of the "Golden Rule." According to Song (2002), the Confucian Golden Rule is to empower and serve people. Wang (1999) suggests that this means "a man of humanity, wishing to establish his own character, also establishes the character of others, and wishing to be prominent himself, also helps others to be prominent” (p. 422). Confucius postulated that learning holds two purposes: (a) learn to be and upright and moral person (i.e., superior man or junzi), and (b) apply what has been learned to serve people via the state. For social workers, this means that leaders must adhere to the social work code of ethics and then model these values to their co-workers and clients for the betterment of society.

It is possible to view how Confucius himself was a transformational leader in his times. He expounded and practiced the skills of negotiation, participation of all, and empowerment (Bass, 1985). Confucius stated, "As for the humane, while they want to establish themselves, they establish others. While they want to succeed themselves, they help others to succeed. They can draw lessons from nearby. These can be called methods of humanness" (Analects, 6: p. 30). This point is especially relevant to social work leaders, in that agency and community-based leaders will take part in decisions that will impact the ability of clients to experience growth and empowerment in their lives.

\subsubsection{Intellectual Stimulation}

This dimension of transformational leadership has to do with getting followers to think about old problems in new ways. Transformational leaders delegate responsibility and authority to followers so that they empower followers to accomplish organizational goals in a relatively autonomous manner. The status quo is questioned, and new innovative methods for developing the organization and accomplishing its mission are explored (Bass, 1985). Risk-taking behaviors and autonomy are trademarks for people who value individuality, egalitarianism, and open-mindedness. Openness ensures that they see new ways of thinking as something that contributes to leadership effectiveness. In fact, they may see the leader's role as instigating and stimulating new ideas. Anyone can do the same thing better, but for those with less traditional values, the leader is the one who envisions and stimulates new directions.

Fernandez (2004) provides evidence that Confucius' tenets are consistent with the concept of intellectual stimulation. For example, he notes that Confucius encouraged creativity and independent thinking among his fol- 
lowers. As noted earlier, Confucius also advocated for universal education and believed that if people are educated properly to think for themselves and to adopt the positive traits values of benevolence [ren], righteousness [yi], propriety [li], wisdom [zhi], and trustworthiness, [xin], and are guided by moral leaders, they will cultivate a strong moral character and embrace virtue above all other things and, in so doing, transform themselves and society.

Paul et al. (2000) identified characteristics of leaders who foster empowerment in organizations. These characteristics included charisma, showing a high concern for people, inspirational motivation, and helping staff members achieve goals that are important to them, and the ability to provide intellectual stimulation. The ability of leaders to provide intellectual stimulation seems to occur when leaders are able to inspire and empower others. This in turn seems to create an atmosphere in which the work becomes stimulating, motivating, challenging, and fascinating (Bennis \& Goldsmith, 2003). By building on their strengths and enhancing their knowledge and skills, leaders can have a transforming effect upon the lives of their employees by helping them stay engaged and competent in their chosen career.

For the social work leader, they may find that at times they are acting as a coach and educator by offering opportunities to assist followers to learn and improve their skills. This idea was certainly supported by Confucius. For Confucius, every person was potentially educable and he viewed education as essential. So, by providing professional development, social work leaders show that an investment in people offers significant benefits to the worker, the organization, and one might argue, even society. Confucius trained his disciples to view service to the state and society as very important. Social work leaders must explore ways to provide institutional support for ongoing, experiential learning and development for agency personnel. Again this is consistent with Confucius' focus on education and service.

\subsubsection{Inspirational Motivation}

This refers to a leader's enthusiasm and optimism in articulating a clear, compelling vision, which results in stimulating a similar feeling among followers and helps a group of people towards its goals (Bass, 1985). Others suggest that the inspirational leader always talks optimistically about the future and also talks enthusiastically about what needs to be accomplished. In addition, inspirational leaders support staff to envision attractive future states and they motivate their staff to achieve organizational goals (Avolio \& Bass 2004). In essence, the leader uses his or her vision to create meaning and symbols for followers, in order for them to change (Aldoory \& Toth, 2004). Through inspirational motivation, transformational leaders are able to draw team members around a vision of what the organization can be in the future. By setting high expectations for the organization as a whole and behaving in ways that are congruent with those expectations, transformational leaders are able to inspire their subordinates to hold similar expectations and to work toward realizing those expectations.

Persistent themes contained within inspirational motivation are to: (a) inspire a shared vision in pursuit of a grand ideal, (b) create personal relationships that bring out the best in others, and (c) make efforts to create a better world (Cameron, 2003). The idea of "creating a better world" is a theme that is very consistent with Confucius. Confucius believed that a better world starts with each of us. As he noted, "To put the world right in order, we must first put the nation in order; to put the nation in order we must first put the family in order; to put the family in order, we must first cultivate our personal life; we must first set our hearts right” (Confucius, 1992: p. 34). Therefore, it seems critical that leaders who wish to inspire others must first set their own hearts right. In essence, inspiration is derived from the virtue displayed by the leader. The Confucian paradigm puts forth the notion that collective action can be directed through individuals leading one another through virtuous behavior. Confucius believed that moral models have magnetic power, and virtuous individuals can bring about change through their actions by inspiring others to change themselves (Confucius, 1992: p. 12).

\subsubsection{Individualized Consideration}

This term refers to efforts on the part of a leader to provide emotional and social support to their followers and to develop and empower them through coaching, mentoring, and growth opportunities (Bass, 1985). Burns (1978) says leaders who exhibit individualized consideration "deal with others as individuals; consider their individual needs, abilities, and aspirations; listen attentively; further their development; advise; teach; and coach" (p. 4). Leaders who are effective at individual consideration are better able to delegate responsibility, empower people, support their subordinates, and be responsive to individual needs. In essence, they listen, communicate, and encourage.

Individualized consideration underscores the necessity of altruism if leadership is to be anything more than 
authoritarian control. To this end, the concept of individualized consideration fundamentally mirrors the Confucian philosophy of benevolence, or "ren" in Chinese. Dubs (1951) indicates that the fundamental concept of virtue in Confucianism is the term "ren." However, according to Dubs, there have been different translations for ren, such as benevolence, perfect virtue, the Good, humanity and benevolent love. Confucius himself defined it by the ordinary Chinese word for "ai", meaning love. In fact, the pronunciation of the world ren in Chinese is the same as that of the word "human." Thus, Confucius defined ren as not only an essential human quality, but also implied that it takes more than a single human to express benevolent love to one another. Confucius made benevolent love the center of his ethical teaching. Therefore, leaders need to be willing to set aside their own self-interests and model behaviors that demonstrate the leader's commitment to helping others and a "love" for those who follow.

\subsection{Application to Social Work Leadership}

In the introduction to this paper it was noted the literature on "leadership" in social work practice is relatively limited at this point in time (Kirkpatrick \& Ackroyd, 2003). Instead, there has been an emphasis on the management and supervisory aspects of social work practice (Lawler, 2008). It should be recognized that social work administrators/leaders do need to be able to focus on the tasks at hand in fulfilling their "managerial" roles, as in reality, social service agencies are essentially businesses that must at least break even in order to stay in existence. However, it is also important that decisions made within agencies should come from a deep, moral source. For this reason, it seems that the philosophy put forth by Confucius on moral leadership is especially relevant to social service agency leaders who may feel they are working in a moral vacuum. It should also be noted that the ideas on moral leadership are highly consistent with the Code of Ethics practiced by social workers in the profession.

It might be easier to relate the principles of Confucian moral leadership through the use of an example in a social service agency setting. The author will then offer specific recommendations for social work administrators/leaders based upon the teachings of Confucius. The agency used in this example is not based upon any one organization, but rather, it is an amalgamation of several agencies which the author worked as a social worker within the social service context over a ten year period.

\subsection{Summary of the Social Service Agency Used in Application Example}

The social service agency used in this example is a small case management organization designed to serve youth and families deemed "at risk" for eminent placement of the child outside the family unless intensive and individualized services are provide to the youth and his or her family. The agency is directed by an MSW level social worker who also provides direct assessment services within the agency. There are also three other workers who provide intensive assessment services to families; one is a nurse practitioner and the other two are also MSW level social workers. There are also ten bachelor-degreed case managers who engage in the monitoring, tracking, and assisting clients to navigate the myriad of agencies in the local and extra-local social service delivery system. A conscious effort was made by the founding director of the agency to locate the organization in an area of high need. It was also located in a locale with easy access by bus or on foot to better serve residents. As noted earlier, the clients of this agency are youth and their families who have multiple needs and who are at risk for the youth being removed from the home and placed in sort type of institutional setting (e.g., residential treatment center, incarceration, psychiatric facility). The agency provides services to a wide range of clients in terms of race/ethnicity, SES, family constellation, and other demographic variables.

\subsection{Application of Concepts to Agency Example}

In the following section, practical recommendations and implications for social service administrators/leaders based upon the agency example will be discussed in the context of the synthesis of Boss's four components of transformational leadership and Confucian philosophical teachings.

\subsubsection{Individualized Consideration}

From previous sections in this paper, it has been noted that Confucius advocated that a primary focus of a leader should be to empower and serve the people. The leader who follows this component will make efforts to explore the various desires and problems of agency personnel and in turn make efforts to address these areas. Effective 
agency administrators/leaders make genuine efforts to position themselves to have quality communications with their personnel to facilitate the discussion of the employee's needs. In the agency example presented earlier, the director worked with personnel to determine what their individual continuing education needs were in order to help them be better at their jobs. For example, one recently hired worker noted her desire to learn more about the process in the local child protective service agency so that she might better understand what her clients experienced in their dealings with the child protective service system. The director worked with the employee to connect with the local child protective service agency to arrange a time for the worker to visit the child protective service agency and talk with their workers about their jobs and their views on clients. In this example, the director took an active role in both listening to the needs of the employee and then taking action to address the voiced concern.

It is important to reiterate that the information the newly hired worked shared could only occur in the context of a leader-worker relationship in which it was deemed safe to discuss areas to improve within a particular worker. A leader will have difficulty following a transformational style, as well as follow the tenets of Confucius if they only focus on one aspect of the approaches to leadership. Leaders should attempt to view their efforts in a holistic manner in which they need to act on the entirety of transformational leadership and Confucian teachings.

\subsubsection{Idealized Influence}

Transformational leaders attempt to find ways to gain the admiration, respect, and trust of their staff (Bass, 1985). One way that leaders can gain the admiration and trust of their staff is to be an effective role model. In the previous example, we explored the importance of individualized consideration for leaders as they attempt to meet the distinct needs of each staff member. We also noted that this is only possible if an atmosphere of trust and safety is created by the leader. It seems important that leaders model how to take safe risks in the workplace. For example, the director of the agency in the example used a practice called "celebrating our mistakes" during staff members. The director modeled how to openly admit to a mistake he made during an assessment interview. He noted how he had neglected to explore a health issue in more depth and how that had impacted the referrals suggested for the family. The director later discovered his mistake and re-visited the topic of health concerns and discovered an issue that led to an additional referral for the family; a referral that led to much more favorable outcomes for the family members. The director shared this "failure" with the staff and then "celebrated" what had been learned from the mistake. By doing this activity, the director modeled a healthy way to share very delicate and sensitive information with co-workers in a way that all could learn from the mistake of one.

In this example, the modeling activity of the director could empower staff members to discuss their needs and concerns, even shortcomings, in a way that allows them to grow and become empowered as workers. Confucius discusses the importance of the leader as role model as a means to empower others. As noted earlier, this type of activity is similar Confucius' writings about his notion of the "Golden Rule." According to Song (2002), the Confucian Golden Rule is to empower and serve people. When a leader is able to honestly and openly share his or her mistakes, the possibility exists that others in the agency will feel empowered to do the same in the quest for improvement

\subsubsection{Intellectual Stimulation}

The transformational leader attempts to stimulate independent thought and creativity in staff members (Bass, 1985). As noted earlier, transformational leaders delegate responsibility and authority to followers so that they empower followers to accomplish organizational goals in a relatively autonomous manner. It would seem that leaders who wish to engage in intellectual stimulation are also open to a democratic approach to decision making within an organization. It suggests that as agency administrators consider polices that affect workers and service provision in an agency, it is imperative that an inclusive approach be used in such a manner that personnel feel that they have a say in the policies that govern their agency. In the case example in this paper, the director was faced with decisions about staffing for services to clients. The issue was that "traditional" 9 - 5 hours did not always work well for clients because they worked during the day and setting an appointment during their work hours often meant lost wages as they were typically employed in "secondary labor market" jobs that offer few job benefits (Doeringer \& Piore, 1971). The director took a democratic approach to solving this issue by taking it to the staff and facilitating an open dialogue to develop a creative solution to the problem. The director and staff worked out a solution that involved rotating coverage for after hour appointment times for clients. This democratic approach led to a creative solution that left the workers feeling included and empowered.

Confucius believed that were five cornerstones (also known as the Five Bonds or Relationships) of societal 
relationships: (1) ruler and subject; (2) father and son; (3) husband and wife; (4) elder brother and younger brother; and (5) friend and friend. With the exception of the last, all are hierarchical, and all imply mutual obligations (Luo, 1997). For the transformational leader, it seems important that they pursue the "friend and friend" relationship within their organization. It corresponds with the Confucian tenet of Ren. To live by Ren is to try to see things from other people's perspectives, and then to do one's best for them with that in mind (Analects 6.30). This is how friends often interact with each other. Confucius believed that everyone should follow Ren. To live by Ren, people must reciprocate with compassion. This is analogous with the Golden Rule of Confucius. For the leader who adopts Ren, he or she should make an effort to empathize with their staff and find ways to elevate and empower personnel within the organization. As noted in the example, the director of the agency did make an effort to understand the views of the agency staff in a manner that led to a democratic and mutually acceptable solution, similar to the way that friends would make a decision.

\subsubsection{Inspirational Motivation}

As noted earlier, this term refers to a leader's enthusiasm and optimism in articulating a clear, compelling vision, which results in stimulating a similar feeling among followers and helps a group of people towards its goals (Bass, 1985). An agency director can seek to provide inspirational motivation by bringing staff and other stakeholders together through common values, beliefs, and ideas about how to best serve clients. It is important that transformational leaders avoid imposing their own values and beliefs upon staff, but rather, work to empower agency personnel to develop a set of mutually acceptable values and beliefs that will guide the professional behaviors of workers in the organization. Communication is a critical skill for the transformational leader in bringing together agency workers around these shared values and beliefs. The leader must be well-versed in communication skills that encourage open dialogue in a manner that contributors feel both inspired to do so as well as safe. Organizational retreats were used by the agency director in the case example as a means of providing inspirational motivation. Well-run agency retreats can be a way to create a safe environment where colleagues can step out of their normal roles and functions and enter into a safe zone of creative conversation about agency values, beliefs, and ideas, as well as their own professional growth aspirations. The director also explored other safe places for conversation such as traveling in cars with colleagues, where there is a certain intimacy created by being in close proximity over an extended time.

As noted earlier, Confucian teachings state that collective action can be directed through individuals leading one another through virtuous behavior. Confucius believed that moral models have magnetic power, and virtuous individuals can bring about change through their actions by inspiring others to change themselves (Confucius, 1992: p. 12). In the case example, the leader used organizational retreats and other safe places for conversation to model such skills as empathic listening, sharing knowledge, providing and accepting support, and other communication skills and activities to invite agency staff to participate, and in turn, be open to making changes in themselves.

\subsection{Caveats on Use of Confucian Teachings for Leadership in Social Work}

There are numerous critiques of Confucian teachings as applied to the modern world. In this paper I would like to briefly discuss two issues: (1) sexism, and (2) autocratic leadership.

\subsubsection{Sexism}

As noted earlier, each of the Five Relationships, with the exception of friend to friend, is based upon a hierarchy. They contain superior and subordinate roles. Both the superior and the subordinate have their duties and obligations, but the basis is fundamentally in the context of superior and subordinate. Thus the Confucian relationship of husband-to-wife by definition puts the woman in a subordinate role to the male. At this point, it might be tempting to simply dismiss all of the teachings of Confucius. Obviously, social work administrators/leaders are not interested in perpetuating a patriarchal system within their organization. In answer to this dilemma, I would suggest that readers of Confucius take an approach similar to those who struggle to find relevancy with the theories of Sigmund Freud. Many within our profession have dismissed the work of Sigmund Freud as sexist because of such views expressed by Freud that women are "mutilated and must learn to accept their lack of a penis" (Ettinger, 2007). Others note that this is a bit like throwing out the baby with the bathwater. There are numerous concepts from Freudian theory that are helpful in our understanding human behavior. One feminist critic of Freud suggested that his theories could be somewhat repaired by replacing the word "penis" in his writings with 
the word "power" (Firestone, 1970). Likewise, current feminists have suggested there are still ways to glean important concepts from Confucian teachings that can be applied to modern life. For example, Walker-Vadillo (2009), notes that while the relation between the husband and wife shows the position of the woman as one subordinate to the husband within the marriage, this may not actually indicate a systematic discrimination against women in Confucius' philosophy. As Walker-Vadillo states, "In Confucian social relations, the principle of humanity is the measurement of all action, and it must be reciprocated. If we analyze women's position in Confucianism, even when a woman is not her husband's equal, he owes her respect, generosity, tolerance, and kindness, attributions that greatly differ from the current social injustices that women suffer in neo-Confucian states" (p. 2).

Yin (2006) addresses the issue of sexism by advocating for a synthesis of feminism and Confucian teachings in what she terms "Confucian Feminism." It is her contention that current feminist theorists have much to gain in contesting sexism by incorporating Confucian teachings into their ideas. Yin encourages us to look beyond the time-based sexist components of Confucian philosophy, and instead explore the critical concepts of ren (humanness) and fen (share) as they relate to social interactions and personal rights. The term fen is an important concept when we discuss the issue of rights of women. Fen differs from the Western notion of rights that views rights as a consequence of social relations or natural talents. Fen is strictly a social product. It is a share of the social good that is created by cooperative efforts of many members in a society (Chang, 1998). Therefore, it could be implied through Confucian philosophy that social issues such as sexism can really only be overcome by the efforts of both women and men. The concept of fen is closely connected to the term ren. As noted earlier, Confucius made benevolent love (ren) the center of his ethical teaching. Leaders who become aware of sexism in the workplace are in essence "duty-bound" to address this ethical issue because of their sense of benevolent love.

\subsubsection{Autocratic Leadership}

First it is important that Confucius lived in a period in which Chinese leadership was highly autocratic (Smith, 1973). Therefore, his writings reflected the moral conduct of his time regarding those in power. Confucius believed that while sovereigns should be obeyed, they should have to earn the support of their citizens by showing deference for the people and a sincere commitment to the common good (Smith 1998). Lee (2001) notes that Confucius' teachings are not a perfect match with traditional Western leadership models. Lee summarizes the primary styles of leadership appearing in the Analects as two types: "authoritative" (rather than autocratic) leadership and reciprocally, "humanitarian" leadership. Lee contends that authoritative aspects can be found in Confucius through a connection with "charismatic" leadership styles considered in Western leadership theories. At times, Confucius discusses leadership as a force of personality that encourages not only a high degree of loyalty and dedication to a leader, but also a high degree of trust in a leader. On the other hand, Confucian teachings also seem to match a transformational/democratic leadership model because Confucius also encourages leaders to enhance positive moral values and higher-order needs of subordinates (Lee, 2001). This in turn creates a reciprocal relationship between the leader and followers in such a manner that could reduce the autocratic propensities promoted by some Confucian-based leaders (Luo, 1997).

\section{Conclusion}

As noted earlier, there has been a movement from looking strictly at the "managerial" aspects of administration in the social services and nonprofit sectors and instead exploring the issue of "leadership." This shift has led to the realization that the administrative behaviors of a leader may be shaped less by technical decision-making tools than by the "vision" and "values" held by a leader. The vision and values of a leader can be influenced by a wide range of ideas and cultures. This paper presented a synthesis of the teachings of the Chinese philosopher Confucius in relationship to the four components of the western culture-based transformational leadership theory as a viable source of information for administrative decision-making in the social services and nonprofit sector. The case analysis in the paper demonstrated practical suggestions on how to synthesize the teachings of Confucius with transformational leadership theory.

Confucius fashioned a model of leadership that challenges the leader to strive toward perfection, who is both idealistic and realistic, as Fernandez (2004) notes.

For this leader, carrying on his task is the very essence of the development of the perfection of his responsibility. Through her actions, the leader improves the world and brings harmony to all. He or she is a leader who 
delivers results that go beyond short-term profit, a leader with a vision of a better society, a better life and a better place to work (p. 29).

The decisions made by a leader following the teachings of Confucius will be based upon virtue and in a manner that displays the humility of the leader. As Confucius stated, "Humility is the solid foundation of all the virtues".

\section{References}

Aaltio-Marjosola, I., \& Takala, T. (2000). Charismatic Leadership, Manipulation and the Complexity of Organizational Life. Journal of Workplace Learning, 12, 146-164. http://dx.doi.org/10.1108/13665620010332750

Aldoory, L., \& Toth, E. L. (2004). Leadership and Gender in Public Relations: Perceived Effectiveness of Transformational and Transactional Leadership Styles. Journal of Public Relations Research, 16, 157-184.

Avolio, B. J., \& Bass, B. M. (2004). Multifactor Leadership Questionnaire. Manual and Sampler Set (3rd ed.). Redwood City, CA: Mindgarden. http://dx.doi.org/10.1207/s1532754xiprr1602_2

Bass, B. (1985). Leadership and Performance beyond Expectations. New York: Free Press.

Bennis, W., \& Goldsmith, J. (2003). Learning to Lead (3rd ed.). New York: Basic Books.

Bennis, W., \& Nanus, B. (1985). Leaders: The Strategies for Taking Charge. New York: Harper and Row.

Burns, J. M. (1978). Leadership. New York: Harper \& Row.

Chan, G. K. Y. (2008). The Relevance and Value of Confucianism in Contemporary Business Ethics. Journal of Business Ethics, 77, 147-360.

Chin, A. (2007). The Authentic Confucius: A Life of Thought and Politics. New York: Scribner.

Confucius, \& Lau, D. C. (1992). Confucius: The Analects. Hong Kong: Chinese UP.

Doeringer, P. B., \& Piore, M. J. (1971). Lnternal Labor Markets and Manpower Analysis. Lexington, MA: Heath Publishing.

Ettinger, B. (2007). Diotima and the Matrixial Transference: Psychoanalytical Encounter-Event as Pregnancy in Beauty. In C. Van der Merwe, \& H. Viljoen (Eds.), Across the Threshold. New York: Peter Lang Publishing.

Fernandez, J. A. (2004). The Gentleman’s Code of Confucius: Leadership by Values. Organizational Dynamics, $33,21-31$. http://dx.doi.org/10.1016/j.orgdyn.2003.11.007

Firestone, S. (1970). The Dialectic of Sex: The Case for Feminist Revolution. New York, NY: Farrar, Straus and Giroux.

Fisher, E. (2009). Motivation and Leadership in Social Work Management: A Review of Theories and Related Studies. Administration in Social Work, 33, 347-367. http://dx.doi.org/10.1080/03643100902769160

Kirkpatrick, I., \& Ackroyd, S. (2003). Transforming the Professional Archetype? The New Managerialism in UK Social Services. Public Management Review, 5, 511-531. http://dx.doi.org/10.1080/1471903032000178563

Lagos, M. (2004). Leadership and Management: A Strategy for the Social Care Workforce. Leeds: Topss England.

Lawler, J. (2008). Leadership in Social Work: A Case of Caveat Emptor? British Journal of Social Work, 37, 123-141. http://dx.doi.org/10.1093/bjsw/bch404

Lee, J. (2001). Confucian Thought Affecting Leadership and Organizational Culture of Korean Higher Education. Radical Pedagogy, 3. http://radicalpedagogy.icaap.org/content/issue3_3/5-lee.html

Luo, Y. (1997). Guanxi: Principles, Philosophies, Implications. Human Systems Management, 16, 43-51.

Mary, N. L. (2005). Transformational Leadership in Human Service Organizations. Administration in Social Work, 29, 105118. http://dx.doi.org/10.1300/J147v29n02_07

Mizrahi, T., \& Berger, C. S. (2001). Effect of a Changing Health Care Environment on Social Work Leaders: Obstacles and Opportunities in Hospital Social Work. Social Work, 46, 170-182. http://dx.doi.org/10.1093/sw/46.2.170

Mizrahi, T., \& Berger, C. S. (2005). A Longitudinal Look at Social Work Leadership in Hospitals: The Impact of a Changing Health Care System. Health and Social Work, 30, 155-165. http://dx.doi.org/10.1093/hsw/30.2.155

Smith, D. H. (1973). Confucius. New York: Charles Scriber's Sons.

Song, Y. B. (2002). Crisis of Cultural Identity in East Asia: On the Meaning of Confucian Ethics in the Age of Globalization. Asian Philosophy, 12, 109-125. http://dx.doi.org/10.1080/0955236022000043856

Van Eeden, R., Cilliers, F., \& Van Deventer, V. (2008). Leadership Styles and Associated Personalities Traits: Support for the Conceptionalization of Transactional and Transformational Leadership. South African Journal of Psychology, 38, 253267. http://dx.doi.org/10.1177/008124630803800201

Walker-Vadillo, V. (2009). Analects in Feminine: A Feminist Critique of Confucius’ Text. Unpublished Manuscript, Department of East Asian Studies, University of Catalonia Barcelona. 